\title{
Mentalidade Acadêmica no Ensino de Design: avaliação da percepção subjetiva de professores e estudantes de fatores não cognitivos
}

Ivan Mota Santos

Sebastiana Luiza Bragança Lana

\section{Resumo}

Este trabalho tem como tema principal a configuração mental do aluno no contexto do ensino do Design. Trata-se de uma avaliação comparativa das percepções de professores e estudantes de design sobre temas diretamente ligados a ciência da configuração mental e dos fatores não cognitivos que impactam o ensino. A pesquisa é baseada na avaliação subjetiva dos sujeitos em relação a tópicos ligados a configuração mental e a ciência do aprendizado. Através de questionários enviados em formulários, 70 participantes selecionados, dentre eles 21 professores de design e 49 estudantes apresentaram suas impressões relacionadas a variados fatores relacionados há quatro áreas básicas da ciência da configuração mental. Inicialmente, eles foram apresentados as afirmativas que representam a visão de estudantes sobre aspectos da configuração mental acadêmica. Na sequência, foram convidados a escalar o impacto de fatores não cognitivos na sua vida acadêmica. Posteriormente, responderam a questões ligadas ao desenvolvimento de configuração mental de crescimento e, por fim, responderam a duas questões diretamente ligadas ao senso de pertencimento. $\mathrm{O}$ trabalho revela que é preciso maior entendimento de acadêmicos da área sobre o esforço, a confusão e o erro e seus papéis no aprendizado significativo. Também fica claro que a perseverança acadêmica e as estratégias de aprendizagem utilizadas por alunos devem ser trabalhadas para minimizar o impacto negativo na relação ensino-aprendizagem. Revelou-se a necessidade dos professores entenderem que existe uma necessidade de definição de expectativas elevados dentro do ensino e que o feedback deve ser dado de forma significativa e os elogios de forma cautelosa e técnica.

Palavras-chave: Mentalidade Acadêmica, Design. Avaliação, Percepção 


\section{Academic Mindset and Design Teaching: students and professors non-cognitive factors perception assessment}

Ivan Mota Santos

Sebastiana Luiza Bragança Lana

\section{Abstract}

This work has as its main theme the student's mental configuration in the context of design teaching. It is a comparative assessment of the perceptions of design teachers and students on topics related to the science of mental configuration and the non-cognitive factors that impact teaching. The research is based on the evaluation of applicable criteria in relation to the parameters linked to mental configuration and the science of learning. Through questionnaires sent in forms, 70 selected participants from 21 design teachers and 49 students studying variations related to variables related to four basic areas of mental science. Initially, they were presented as affirmative, which represent a student view of aspects of the academic academic configuration. Subsequently, they were asked to scale or impact non-cognitive factors in their academic life. Subsequently, answer questions related to the development of mental growth configuration and, finally, answer two questions directly related to the sense of participation. The paper reveals the area's greatest academic understanding of effort, confusion and error and their roles in meaningful learning. It is also clear that academic perseverance and learning strategies used by students should be worked to minimize or negatively impact the teaching-learning relationship. Reveal the need for teachers to understand that there is a need to set high expectations within teaching and feedback should be given meaningfully and compliments cautiously and technically.

Key words: Academic Mindset, Design, Evaluation, Perception 


\section{Introdução}

Essa pesquisa se insere no contexto do ensino do design. O propósito deste trabalho é avaliar a percepção de estudantes de design e profissionais com a de professores da mesma área. Esta visão comparativa, tem como objeto central o entendimento dos fatores não cognitivos ligados ao aprendizado. Como parte determinante do entendimento da relação entre ensino e aprendizagem no design, a pesquisa realiza uma comunicação direta com as pesquisas na área da psicologia aplicada à educação.

Esta investigação surge a partir de estudos como de Yeager et al. (2013), que tratam da intervenção na personalidade para reduzir reações negativas de alunos frente à exclusão, Hershkovitz e Baruch (2013) que abordam a relação aluno-professor na era do Facebook da perspectiva do aluno, Farrington et al. (2012) sobre o papel dos fatores não-cognitivos na formação do desempenho escolar, e, por fim, Dweck et al. (2014) que investigam mentalidades e habilidades que promovem a aprendizagem a longo prazo. Foram selecionados aspectos ligados ao entendimento geral dos fatores não cognitivos ligados à performance acadêmica, para mensurar a percepção entre os pesquisados. Estas análises foram estruturadas de forma que possam auxiliar o entendimento da relação entre professores e alunos no contexto da mentalidade acadêmica no ensino do design.

Dentre os aspectos abordados, temos as afirmações ligadas aos aspectos mais importantes dos fatores não cognitivos que afetam a aprendizagem. Posteriormente, foi realizada a mensuração dos aspectos não cognitivos mais importantes no ensino do design. Por fim, investigou-se o desenvolvimento de mentalidade de crescimento e o sentimento de pertencimento dos alunos em relação ao grupo.

\section{A Mentalidade Acadêmica de Estudantes}

O ensino efetivo é comumente relacionado a práticas que levam em consideração a perspectiva do aluno e aumentam seu desempenho em fatores cognitivos como resultado dessa abordagem de compreensão. Mas muitos pesquisadores têm dedicado sua atenção para investigar outros aspectos muito importantes do ensino, associados aos fatores não cognitivos em relação aos comportamentos sociais e psicológicos. Esses aspectos do ensino podem ter grande impacto na aprendizagem e motivação. Yeager et al. (2013) mostra que diferentes alunos podem experimentar o mesmo ambiente de sala de aula de maneiras muito diferentes, o que, por sua vez, pode afetar o aprendizado. Esse estudo, entre outros, revela a importância de estar atento aos fatores não cognitivos que influenciam a aprendizagem. Hershkovitz e Baruch (2013) identificaram cinco afirmações que representam as mentalidades ou crenças dos estudantes que captam a essência dos aspectos não-cognitivos mais importantes que afetam a aprendizagem: 
- "Minha capacidade e competência aumentam com o meu esforço efetivo."

- "Eu pertenço a esta comunidade."

- "Esse trabalho tem valor para mim."

- "Eu posso ter sucesso nisso."

- "Aprendizagem significativa requer luta, confusão e até mesmo erros."

Garantir que essas mentalidades e crenças sejam traduzidas em comportamentos positivos e impactar o desempenho da aprendizagem por meio de estratégias eficazes e outras habilidades de auto regulação é um grande desafio. Positivamente, há um consenso emergente na pesquisa educacional de que os fatores não cognitivos podem afetar profundamente a aprendizagem dos alunos. Farrington desenvolveu um modelo para ilustrá-lo. (Farrington et al., 2012)

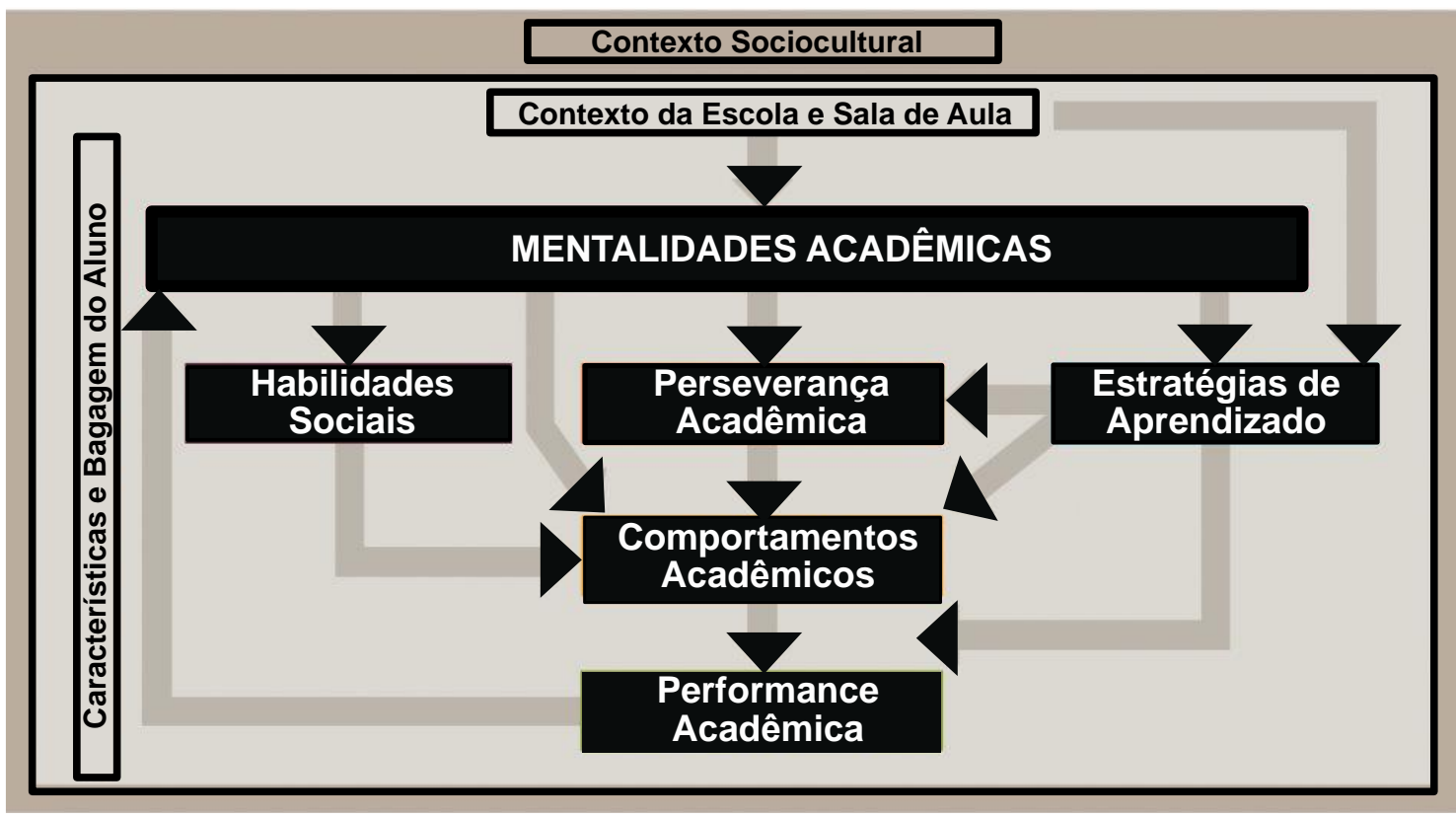

Farrington et al., 2012

\section{Aprendizagem e Mentalidade de Crescimento}

Nas últimas três décadas, dezenas de estudos de pesquisa em ambientes escolares mostraram que as mentalidades dos estudantes, suas crenças sobre inteligência e habilidade, têm importantes implicações para o desempenho acadêmico. E entre as conclusões mais surpreendentes está o fato de que os alunos que possuem uma mentalidade de crescimento, ou seja, estudantes que acreditam que sua inteligência pode crescer à medida que aprendem, frequentemente, se apresentam em níveis mais altos do que aqueles que não o fazem. O oposto disso, ou seja, a crença de que nosso nível de habilidade ou inteligência é essencialmente 
imutável, e que alguns simplesmente têm mais do que outros, é chamado de perspectiva mental fixa (Dweck, et. al. 2014).

Outros estudos mostraram que estudantes de mentalidade fixa escondem seu esforço, preocupados em confirmar sua baixa capacidade. Colocando a culpa em professores ou testes em vez de em si mesmos, eles tendem a atribuir seus fracassos a fontes externas. A estrutura de Dweck ajuda a entender por que os alunos respondem de maneiras tão diferentes. É mais provável que fiquemos bem com o fracasso e apenas nos esforcemos mais na próxima vez, se acreditarmos que erros são chances de aprender. Outros estudos, com abordagens relacionadas à plasticidade do cérebro e maleabilidade da inteligência, sugerem que é possível ajudar estudantes com mentalidades fixas, incluindo (Dweck, et. al. 2014).

Dweck (2014) reconhece que podemos realmente mudar a mentalidade dos alunos. "Primeiro de tudo, podemos elogiar com sabedoria, não elogiando a inteligência ou o talento. Isso falhou. Esse elogio cria alunos que são resistentes.” Ela também descreve que em um estudo, "ensinamos a eles que toda vez que eles saem de sua zona de conforto para aprender algo novo e difícil, os neurônios em seu cérebro podem formar novos”. Conexões mais fortes, que, ao longo do tempo eles podem tornar-lhes mais inteligentes. Para entender muitas possibilidades envolvendo fatores não-cognitivos, uma tabela de conceitos importantes foi desenvolvida, baseado neste trabalho. (Dweck, 2014, páginas 14 a 21)

QUADRO 1: Conceitos de fatores não cognitivos

\begin{tabular}{|l|l|}
\hline \multicolumn{2}{|c|}{ CONCEITOS DE FATORES NÃO COGNITIVOS } \\
\hline $\begin{array}{l}\text { PERSEVERANÇA } \\
\text { ACADÊMICA }\end{array}$ & $\begin{array}{l}\text { Foco e auto controle apresentados pelo estudante durante a } \\
\text { execução de tarefas acadêmicas. }\end{array}$ \\
\hline $\begin{array}{l}\text { ESTRATÉGIAS } \\
\text { APRENDIZAGEM }\end{array}$ & $\begin{array}{l}\text { Habilidades e maneiras utilizadas por estudantes para organizar } \\
\text { e completar tarefas e trabalhos acadêmicos. }\end{array}$ \\
\hline $\begin{array}{l}\text { COMPORTAMENTO } \\
\text { ACADÊMICO }\end{array}$ & $\begin{array}{l}\text { Atitudes que estudantes tomam para serem bem-sucedidos, } \\
\text { como completar exercícios, manter frequência em aulas, manter- } \\
\text { se focado e participativo. }\end{array}$ \\
\hline $\begin{array}{l}\text { MENTALIDADE } \\
\text { ACADMICA }\end{array}$ & $\begin{array}{l}\text { Crenças estudantis que alunos possuem sobre aprendizado, e } \\
\text { sobre si mesmos no papel de aprendizes, que podem influenciar } \\
\text { poderosamente seu sucesso acadêmico de formas variadas. }\end{array}$ \\
\hline EARACTERÍSTICAS & $\begin{array}{l}\text { Experiências, habilidades, conhecimento prévio e repertório de } \\
\text { estudantes. }\end{array}$ \\
\hline HABILIDADES SOCIAIS & $\begin{array}{l}\text { Habilidades interpessoais que influenciam como estudantes } \\
\text { interagem e colaboram com outros. }\end{array}$ \\
\hline
\end{tabular}




\section{Desenvolvendo Mentalidades de Crescimento}

A mentalidade de crescimento permite que os alunos melhorem seu desempenho e promovam desafios. Pesquisadores e cientistas cognitivos sugerem que as mentalidades afetam as habilidades sociais, a aprendizagem, os comportamentos e a perseverança nas atividades acadêmicas, i. e., eles podem melhorar e ter um melhor desempenho. Dweck et al. (2014), aponta cinco estratégias que, se aplicadas corretamente, poderiam ajudar os alunos a passar de um ciclo negativo para um mais virtuoso, com cada pequena mudança positiva aumentando o ímpeto para outros comportamentos positivos, encorajando uma mentalidade de crescimento. Eles são: (Dweck, 2014, p.04)

1. "definir altos padrões e expectativas.

2. estabelecer metas alcançáveis de curto prazo.

3. dê um feedback significativo.

4. louvar com cuidado.

5. abraçar a palavra ainda."

A estratégia requer realmente conhecer os alunos e o material, mas, uma vez feito o ajuste dos padrões certos, permite pedir muito deles. O feedback também é uma questão importante. Os alunos devem poder usar de maneira significativa o feedback importante que recebem. Como diz o educador Dylan Wiliam (2010), "a única coisa que importa sobre o feedback é o que os alunos fazem com ele".

Três formas comuns de elogio a serem evitadas são apresentadas: primeiro, evite elogiar por trabalhar duro sozinho por muito tempo. Segundo, evite elogiar os alunos com jargões sem sentido, por algo que não vale a pena e, finalmente, evite elogiar as características pessoais. Todas essas estratégias não vão transformar os estudantes instantaneamente, mas com o tempo, estudos sugerem que esses métodos podem trazer resultados reais e poderosos.

\section{Sensação de Pertencimento / Incerteza}

De acordo com o modelo anteriormente visto, esse tipo de sentimento pode influenciar diretamente o desempenho acadêmico. Em teoria, pertencer à incerteza pode fazer com que eventos normalmente pequenos pareçam grandes. Os pesquisadores sugerem que, quando estamos preocupados com essas questões, nossos recursos cognitivos são prejudicados. Por outro lado, esses estudos mostram que os desempenhos acadêmicos são melhorados se associados a um sentimento positivo de pertencimento. (Walton \& Cohen, et al.) 
(Dunlosky, Rawson, Marsh, Nathan e Willingham, 2013; Walton, Cohen, Cwir \& Spencer, 2012), da Universidade de Stanford, foram pioneiros em dois tipos de intervenções para abordar essas preocupações, cada um deles tem como objetivo enviar mensagens-chave para os alunos afetados:

- Você não está sozinho

- Sentimentos sobre a incerteza de pertencer irão desaparecer com o tempo

Em vários estudos, percebe-se que apenas uma sessão de 30 a 60 minutos trouxe impactos significativos e duradouros. Muitos dos estudos incluíram estudantes mais velhos compartilhando suas experiências iniciais com os alunos mais jovens. Então, os veteranos da faculdade trabalhavam com calouros.

O exercício durou apenas 30 minutos, mas impulsionou o desempenho dos alunos, e o efeito se manteve anos depois. Uma explicação para o impacto desses exercícios de autoafirmação é que eles lembram os alunos sobre o que eles valorizam e suas próprias boas qualidades. Por exemplo, seus interesses pessoais, seus relacionamentos com amigos e familiares. Esta prática é chamada de afirmação de valores.

\section{Método}

O foco desta pesquisa baseia-se na avaliação da mentalidade acadêmica e será destinado a informar a prática docente. Este trabalho é um estudo qualitativo baseado na avaliação subjetiva de aspectos específicos da ciência mental sobre a aprendizagem. Vinte e um professores de cursos de design e quarenta e nove estudantes de design responderam a uma pesquisa contendo dezenove perguntas sobre quatro áreas ou temas principais: a primeira é a mentalidade acadêmica dos estudantes; a segunda, o impacto de fatores não cognitivos na pedagogia do design. Cinco tópicos sobre o desenvolvimento da mentalidade de crescimento foram apresentados a professores e alunos. Finalmente, duas questões sobre o senso de pertencimento em ambientes de aprendizagem de design foram apresentadas para coletar percepções subjetivas. (Quadro 02) 
QUADRO 2: Projeto básico da pesquisa

\begin{tabular}{|c|c|c|}
\hline TEMA & AFIRMATIVAS & MEDIÇÃO / ESCALA \\
\hline $\begin{array}{l}\text { MENTALIDADE } \\
\text { ACADÊMICA }\end{array}$ & $\begin{array}{l}\text { 1. Minha habilidade e } \\
\text { competência crescem com meu } \\
\text { esforço efetivo, } \\
\text { 2. Eu pertenço a essa } \\
\text { comunidade } \\
\text { 3. Esse trabalho tem valor } \\
\text { para mim } \\
4 \text { Eu consigo ser bem- } \\
\text { sucedido nisso } \\
5 \text { O O aprendizado } \\
\text { significativo requer esforço } \\
\text { confusão e até mesmo erros }\end{array}$ & $\begin{array}{ll}\text { - } & \text { Concordo totalmente } \\
\text { - } & \text { Concordo } \\
\text { - } & \text { Neutro } \\
\text { - } & \text { Discordo } \\
\text { - } & \text { Discordo totalmente }\end{array}$ \\
\hline $\begin{array}{l}\text { IMPACTO DE FATORES } \\
\text { NÃO COGNITIVOS }\end{array}$ & $\begin{array}{ll}\text { 1. } & \text { Contexto Sociocultural } \\
\text { 2. } & \text { Mentalidade Acadêmica } \\
\text { 3. } & \text { Habilidades Sociais } \\
\text { 4. } & \text { Perseverança Acadêmica } \\
\text { 5. } & \text { Estratégias de } \\
\text { Aprendizagem } \\
\text { 6. Comportamento } \\
\text { Acadêmico } \\
\text { 7. } \quad \text { Características Pessoais }\end{array}$ & $\begin{array}{ll}\text { - } & \text { Impacto Alto } \\
\text { - } & \text { Algum Impacto } \\
\text { - } & \text { Nenhum Impacto }\end{array}$ \\
\hline $\begin{array}{l}\text { DESENVOLVENDO } \\
\text { MENTALIDADE } \\
\text { CRESCIMENTO }\end{array}$ & $\begin{array}{l}\text { 1. Estabeleça altos padrões e } \\
\text { expectativas } \\
\text { 2. Estabeleça metas } \\
\text { alcançáveis e de curto prazo } \\
\text { 3. Forneça feed-back } \\
\text { significativo } \\
\text { 4. Elogie com cuidado } \\
\text { 5. Incorpore o "ainda não }\end{array}$ & $\begin{array}{ll}\text { - } & \text { Concordo } \\
\text { - } & \text { Discordo }\end{array}$ \\
\hline $\begin{array}{l}\text { SENSAÇÃO } \\
\text { PERTECIMENTO }\end{array}$ & $\begin{array}{l}\text { 1. Ter sentimentos } \begin{array}{r}\text { de } \\
\text { incerteza, ou } \\
\text { pertencimento. }\end{array} \text { não } \\
\text { 2. Procurando ajuda } \\
\text { especializada para incerteza de } \\
\text { pertencimento. }\end{array}$ & $\begin{array}{l}\text { - } \text { Frequentemente } \\
\text { - } \text { Algumas vezes } \\
\text { - } \\
\text { - Sunca } \\
\text { - Sim } \\
\text { Não }\end{array}$ \\
\hline \multicolumn{3}{|l|}{ TOTAL: 19 QUESTÕES } \\
\hline
\end{tabular}

Fonte: Elaborado pelos autores.

Este projeto de pesquisa foi desenvolvido com o intuito de compreender o impacto de fatores não cognitivos na formação em design, por perspectivas comparadas de estudantes e professores.

\section{Resultados e Discussão}

A primeira parte da investigação foi dedicada há elementos que compõem a mentalidade acadêmica de estudantes. A partir de afirmativas estabelecidas em evidências 
empíricas da área de estudos psicológicos, os estudantes de design e professores foram apresentados as cinco afirmativas: 'minha habilidade e competência crescem com meu esforço efetivo', 'eu pertenço a essa comunidade', 'esse trabalho tem valor para mim', 'eu consigo ser bem-sucedido nisso', 'o aprendizado significativo requer esforço confusão e até mesmo erros'.

No gráfico 1, vemos a percepção de professores e estudantes de design sobre habilidade e competência em relação ao esforço. As duas categorias de sujeitos abordados tendem a concordar totalmente com afirmação de que habilidade e esforço estão diretamente relacionados.

GRÁFICO 1: Habilidade e Competência aumentam com esforço aplicado

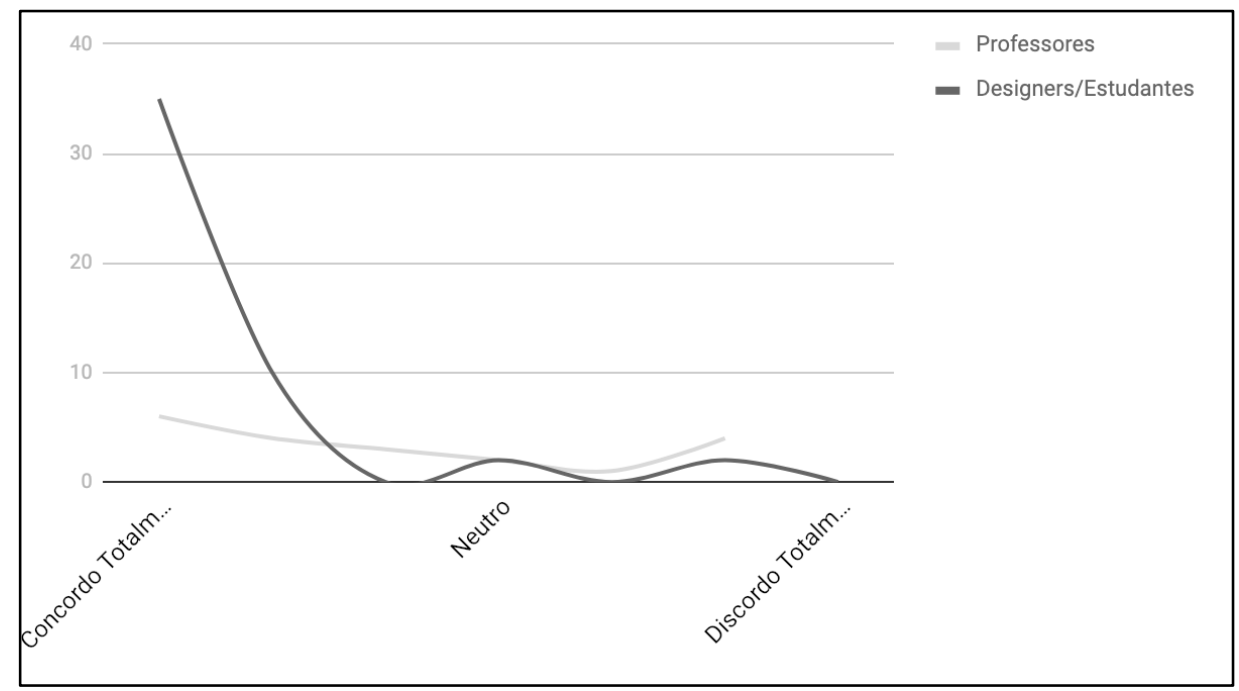

Fonte: Elaborado pelos autores.

Com aparentemente a mesma percepção positiva, mas com alguns sujeitos tendendo a neutralidade ou a discordância, vemos no gráfico 2, a percepção dos entrevistados sobre o pertencimento à comunidade do Design.

GRÁFICO 2: Pertenço a essa comunidade

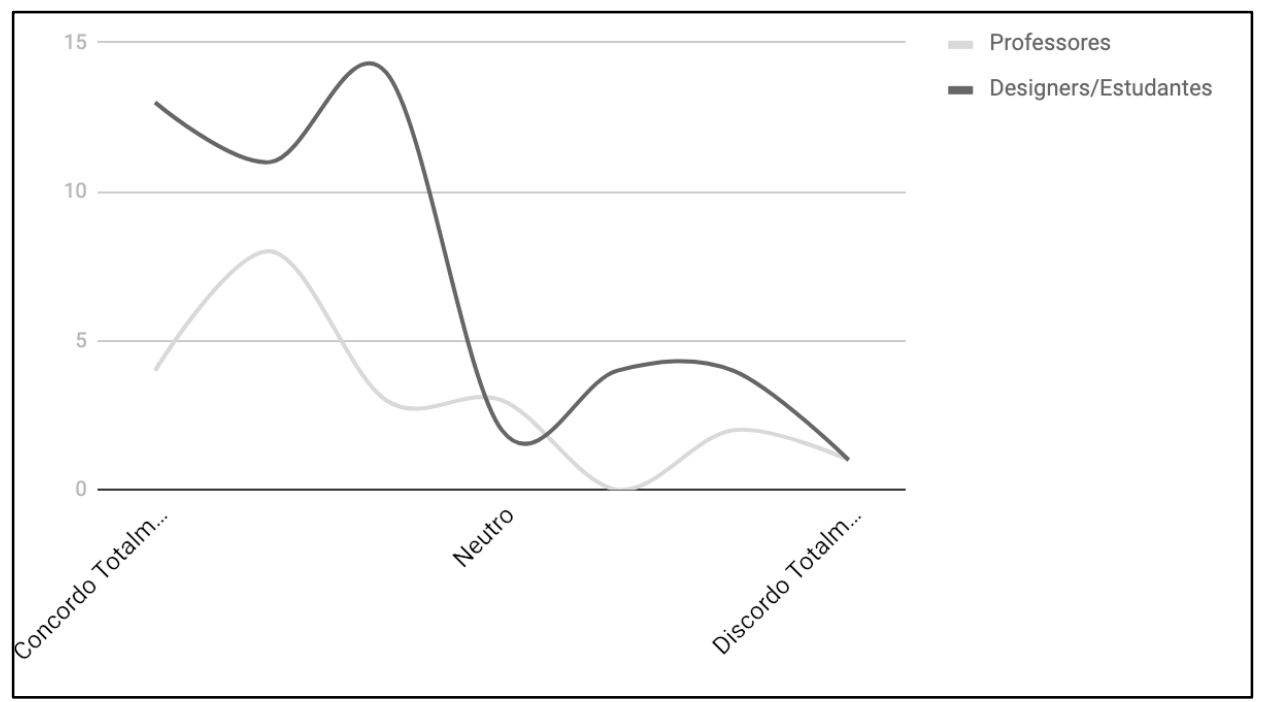

Fonte: Elaborado pelos autores.

ISSN 2526-2882 
No gráfico 3, vemos também um comportamento positivo em relação ao valor do trabalho. Alunos concordam totalmente com afirmação que o trabalho dedicado ao aprendizado do Design tem valor para eles, e, professores afirmam perceber que os alunos dão valor ao seu trabalho.

GRÁFICO 3: Esse trabalho tem valor para mim

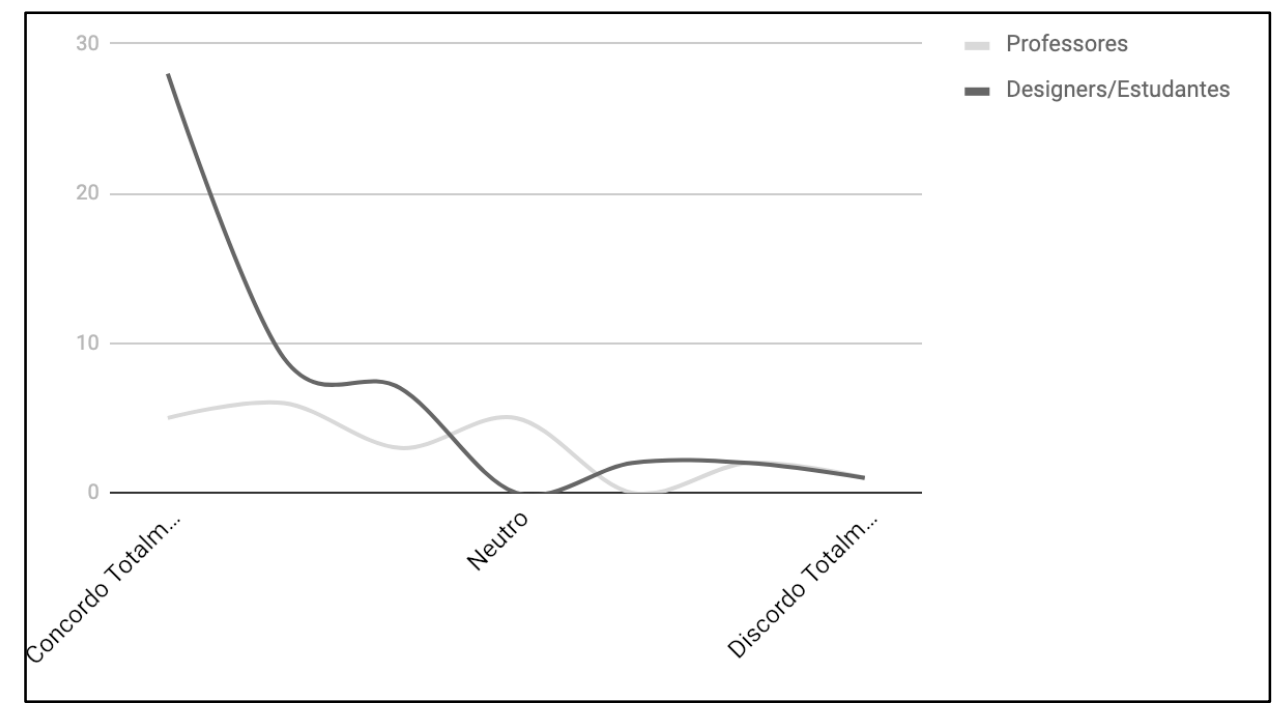

Fonte: Elaborado pelos autores.

Sobre a afirmativa de que podem ser bem-sucedidos no design, tanto alunos e professores tiveram uma postura de concordância, porém, pela primeira vez no estudo, com alto índice de neutralidade, como pode ser visto no gráfico 4.

GRÁFICO 4: Eu posso ser bem-sucedido nesta área

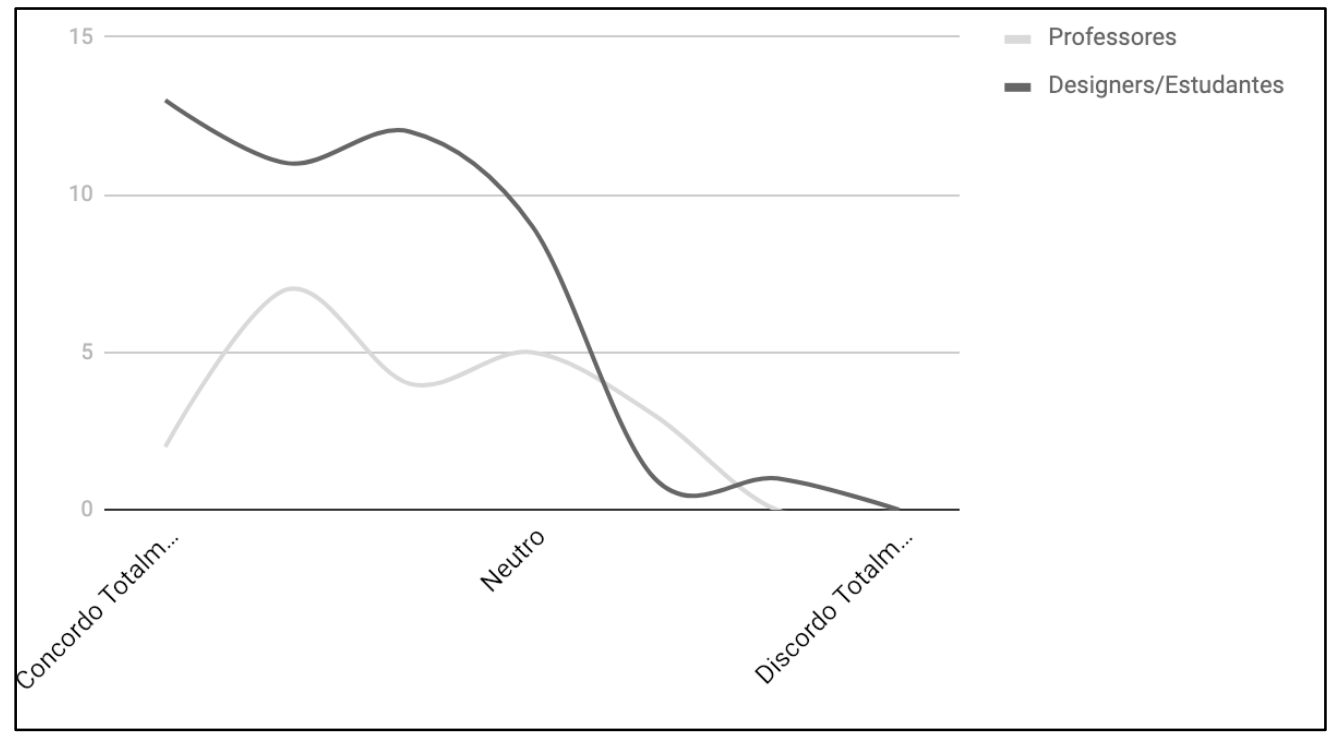

Fonte: Elaborado pelos autores.

ISSN 2526-2882 
No gráfico 5 , vemos o resultado da percepção dos sujeitos da pesquisa sobre a $5^{\mathrm{a}}$ afirmação apresentada. Ela diz respeito ao esforço, confusões e até mesmo os erros necessários para que o aprendizado significativo ocorra. Sobre essa afirmação, estudantes tendem a apresentar uma posição de concordância enquanto professores demonstram ser neutros ou a discordantes.

Este tópico se torna o mais importante resultado da investigação nesta primeira fase. Isso se deve ao fato desse tema demonstrar-se dúbio para professores e estudantes. Como foi apresentado na parte introdutória deste trabalho, os alunos estão de acordo com os mais recentes achados da ciência do aprendizado no que diz respeito aos fatores não cognitivos ligados ao ensino.

GRÁFICO 5: Aprendizado Significativo requer confusão, esforço e erros

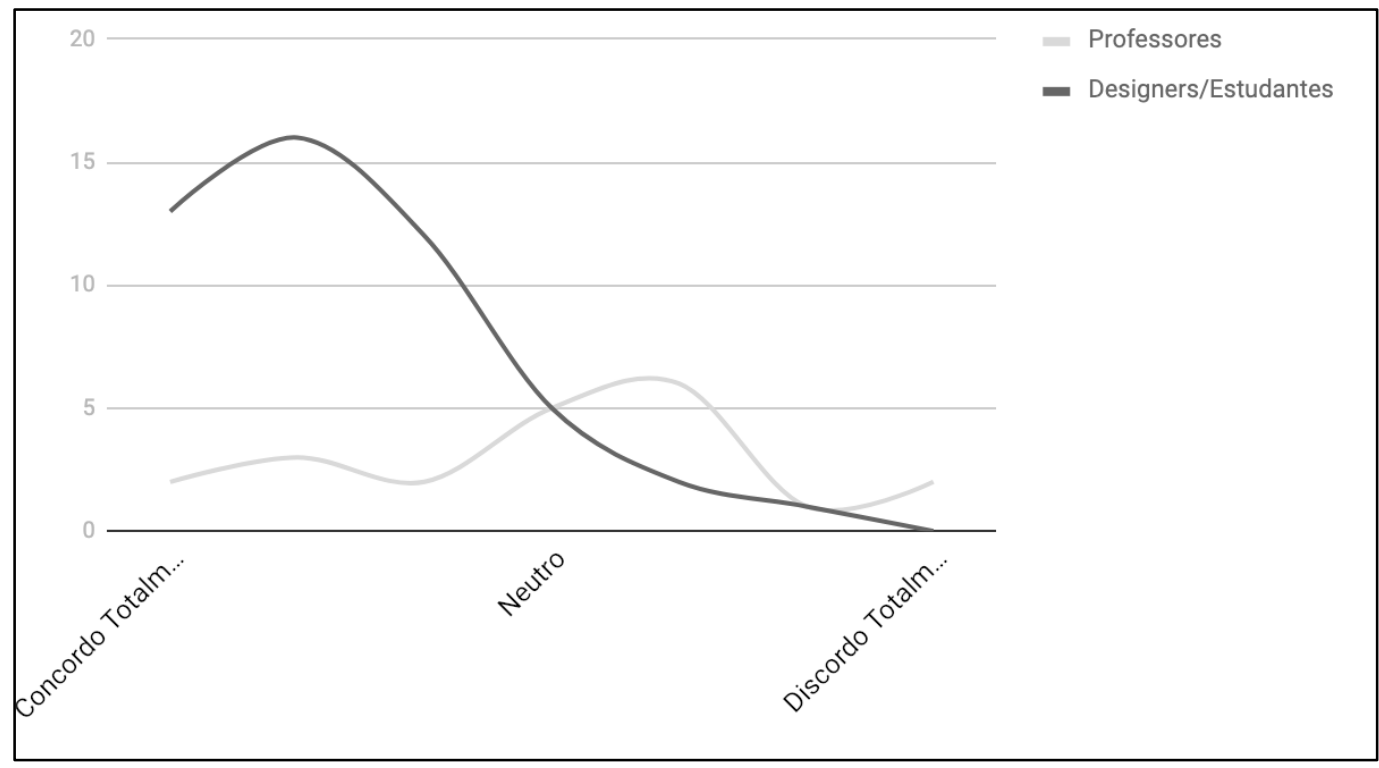

Fonte: Elaborado pelos autores.

\section{Avaliação do Impacto de Fatores Não Cognitivos no Ensino do Design}

Na segunda fase da investigação o foco foi direcionado a medição de impacto dos fatores não cognitivos no ensino do Design para professores e estudantes. Sete fatores foram numerados de acordo com a teoria da área de investigação, sendo eles: o contexto sociocultural, a mentalidade acadêmica, as habilidades sociais, a perseverança acadêmica, as estratégias de aprendizagem, os comportamentos acadêmicos, e, por fim, as características pessoais.

Conforme apresentado nos gráficos 6 e 7, respectivamente, do ponto de vista dos professores e dos Estudantes, a maioria dos itens avaliados foram considerados de "alto 
impacto". Dentre os professores, o contexto sociocultural, as estratégias de ensino, sempre tem impacto na vida acadêmica de seus alunos juntando-se as habilidades sociais. Estes itens não apresentaram perante aos avaliados nenhuma opção de "nenhum impacto".

GRÁFICO 6: Avaliação sobre fatores não cognitivos que influenciam o aprendizado, professores.

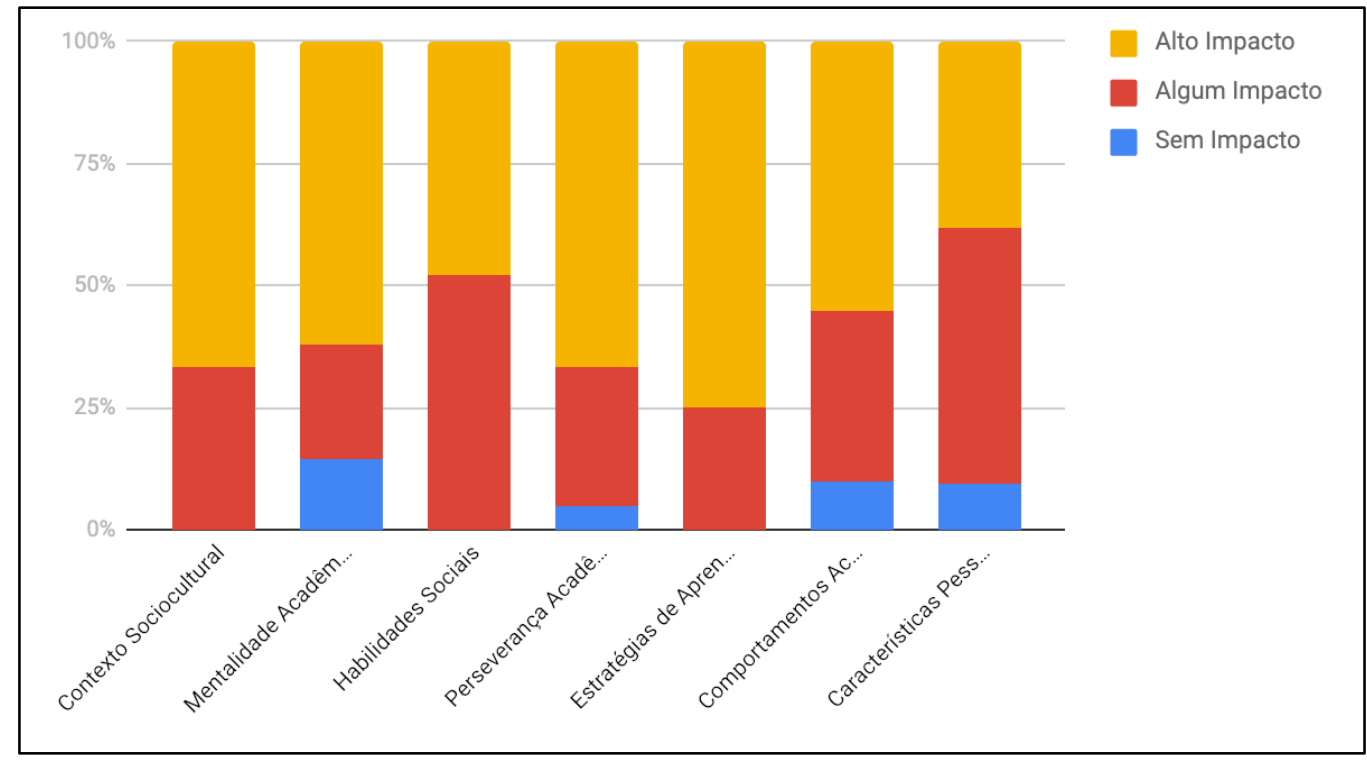

Fonte: Elaborado pelos autores.

Para os estudantes, por sua vez, (Gráfico 7) o único item que unanimemente sempre causa impacto é a mentalidade acadêmica. Para eles, ainda outros fatores de maior impacto são a perseverança acadêmica e o contexto sociocultural.

GRÁFICO 7: Avaliação sobre fatores não cognitivos que influenciam o aprendizado, estudantes.

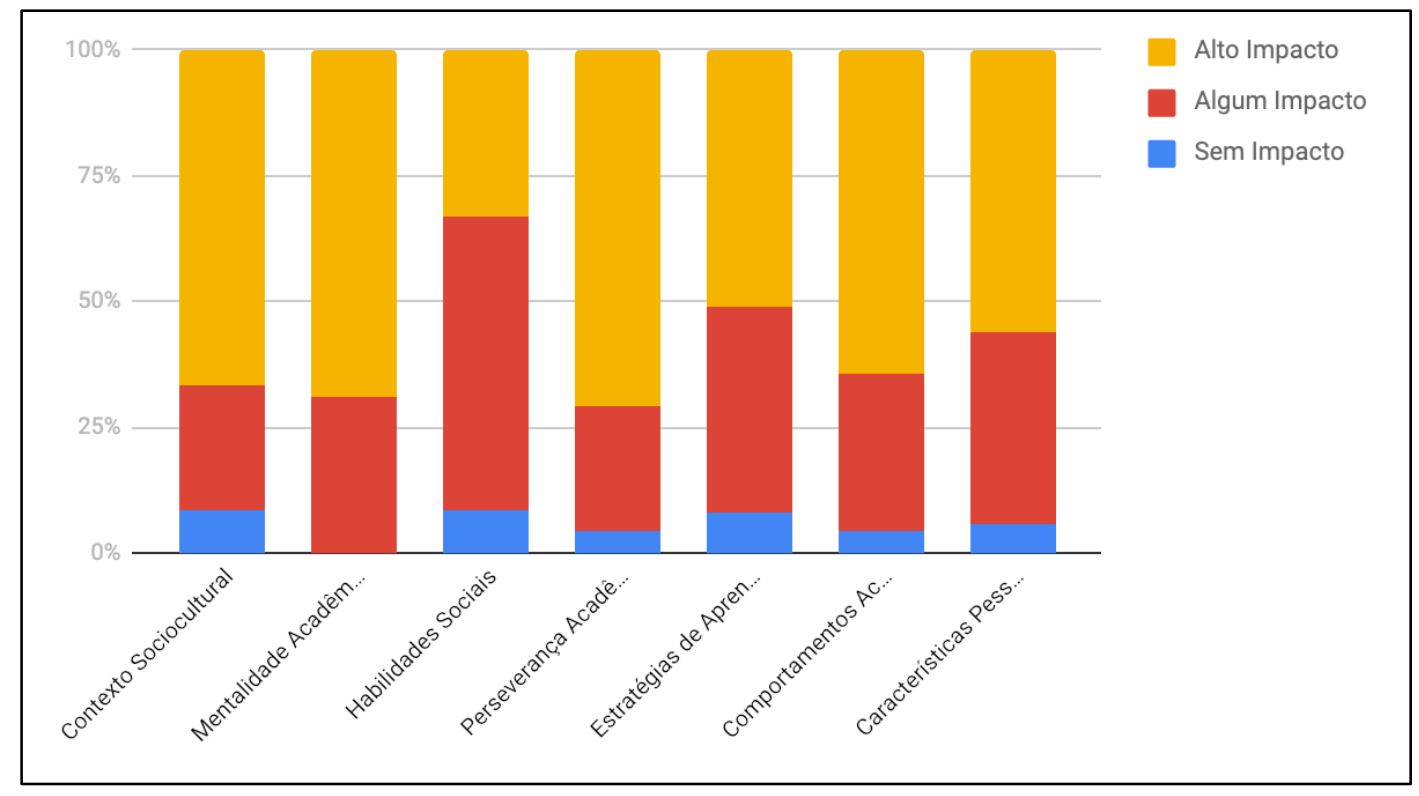

Fonte: Elaborado pelos autores. 


\section{Desenvolvendo Mentalidade Acadêmica de Crescimento}

O desenvolvimento de mentalidades acadêmicas de crescimento, talvez seja o principal tópico para a orientação de práticas instrucionais para melhoria do ensino do Design. Assim, neste tema, buscou-se investigar os fatores de concordância e discrepância no entendimento entre professores e estudantes visando estabelecer parâmetros para o desenvolvimento de tecnologias educacionais ou práticas pedagógicas que venham superar esses problemas.

No gráfico 8, percebe-se que a percepção dos professores de Design em relação as cinco práticas que podem ajudar no desenvolvimento da mentalidade acadêmica de crescimento, conforme mostram evidências empíricas em estudos apresentados na introdução deste trabalho. O único tópico que obteve concordância total dos professores entrevistados está relacionado a oferecer feedback significativo aos alunos. Por outro lado, uma das práticas mais importantes para o desenvolvimento da mentalidade de crescimento ligado a definição de expectativas e padrões altos para os alunos obteve mais de 50\% de discordância dos professores participantes da pesquisa.

GRÁFICO 8: Avaliação sobre práticas de desenvolvimento de mentalidade de crescimento, professores.

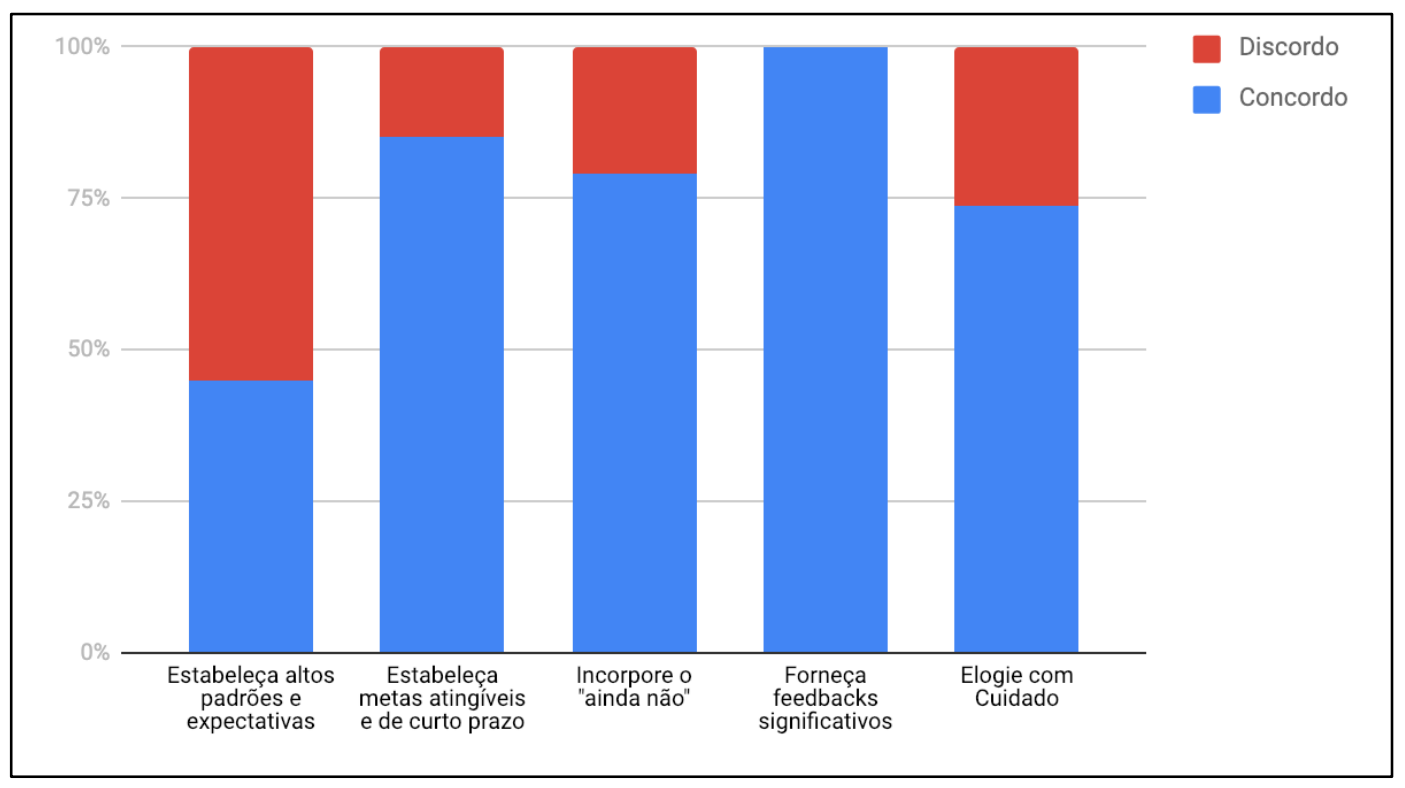

Fonte: Elaborado pelos autores.

Como podemos ver também, no gráfico 9, este mesmo tópico também é o de maior discordância para estudantes de design, mostrando um descompasso da área em relação aos achados da ciência do aprendizado. Do ponto de vista dos alunos, os elementos de maior concordância em relação a essa fase do estudo, dizem respeito ao recebimento de feedback 
significativo, um ponto de destaque positivo também em relação aos professores, e, por fim, o estabelecimento de pequenos objetivos atingíveis e de curto prazo.

GRÁFICO 9: Avaliação sobre práticas de desenvolvimento de mentalidade de crescimento, estudantes.

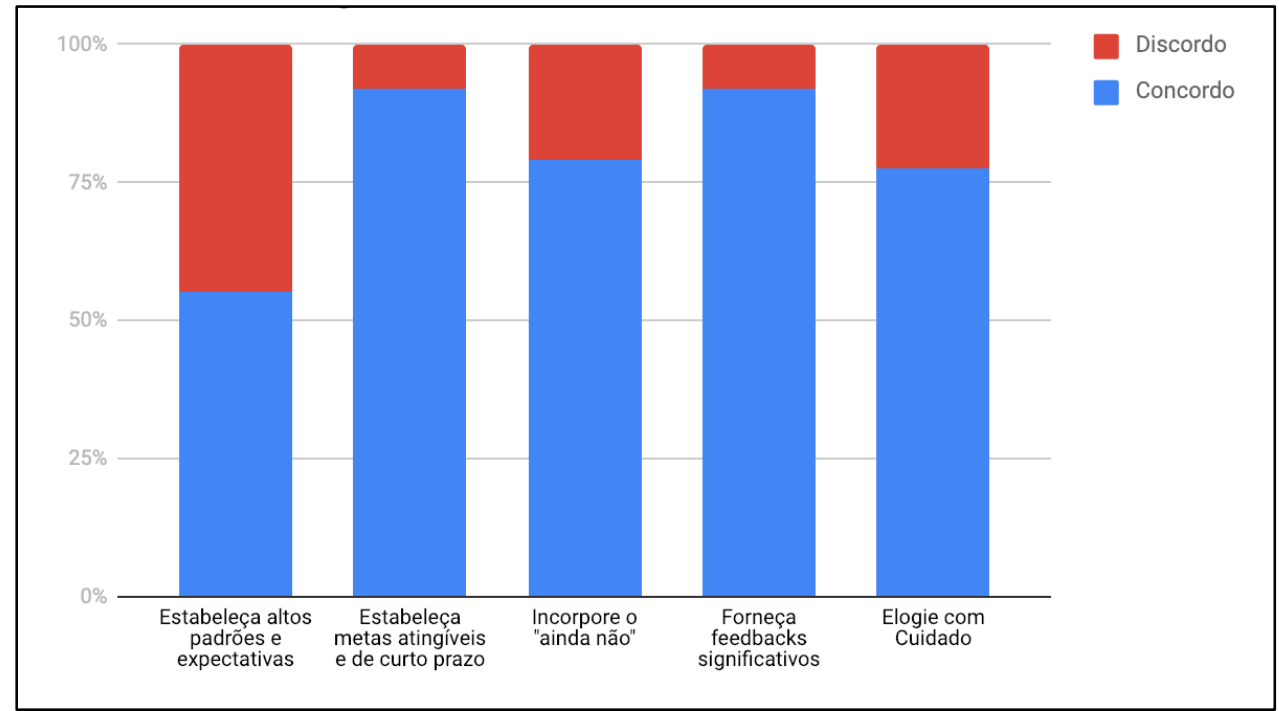

Fonte: Elaborado pelos autores.

Dando continuidade à investigação sobre questões relacionadas ao desenvolvimento de mentalidade acadêmica de crescimento, perguntamos aos professores se seus alunos estabeleciam padrões expectativas elevadas. Além disso, se organizavam seus objetivos em metas atingíveis e de curto prazo. Conforme vemos no gráfico 10, mais de 50\% dos professores tendem a discordar que seus alunos saibam utilizar os recursos citados para o desenvolvimento de uma mentalidade acadêmica de crescimento.

GRÁFICO 10: Avaliação sobre práticas de desenvolvimento de mentalidade de crescimento.

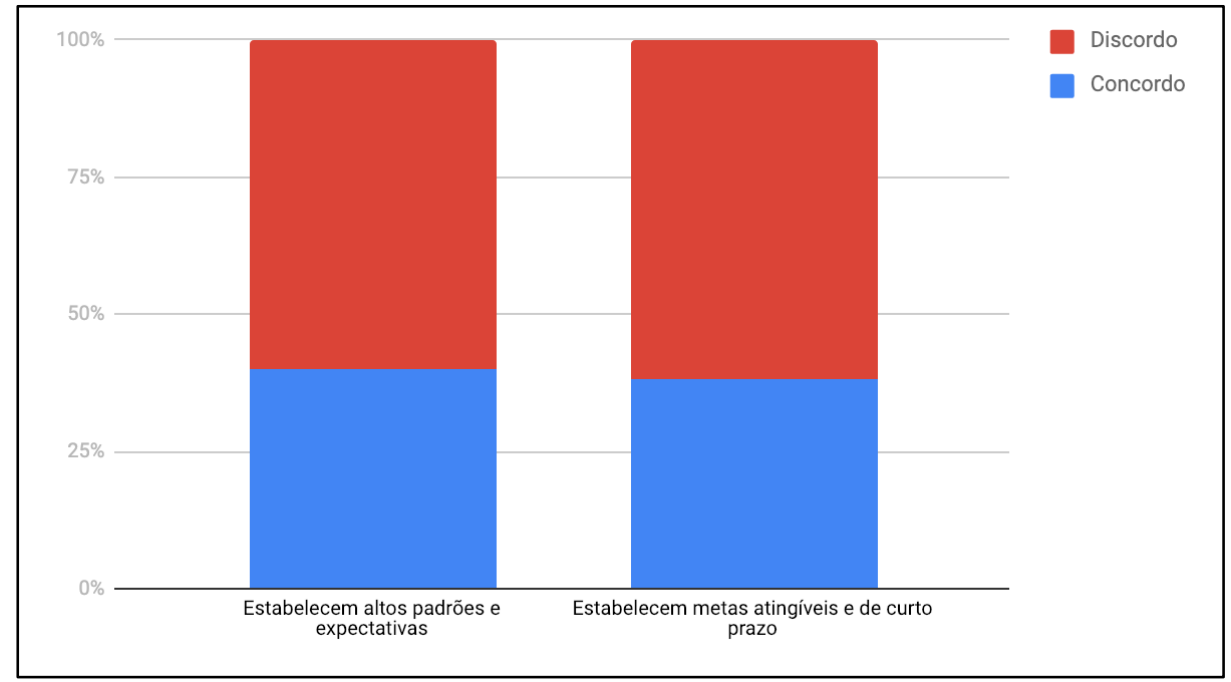

Fonte: Elaborado pelos autores. 
No caso dos estudantes, por sua vez, a visão negativa está ligada a afirmação de que os professores elogiam cuidadosamente em sala de aula. Neste quesito, mais de $50 \%$ dos estudantes entrevistados discordam da afirmação. No caso da afirmação de que os professores oferecem um feedback significativo, quase $75 \%$ dos alunos concordam, mostrando uma situação positiva em relação a esta prática docente. (Gráfico 11)

Gráfico 11: avaliação sobre práticas de desenvolvimento de mentalidade de crescimento.

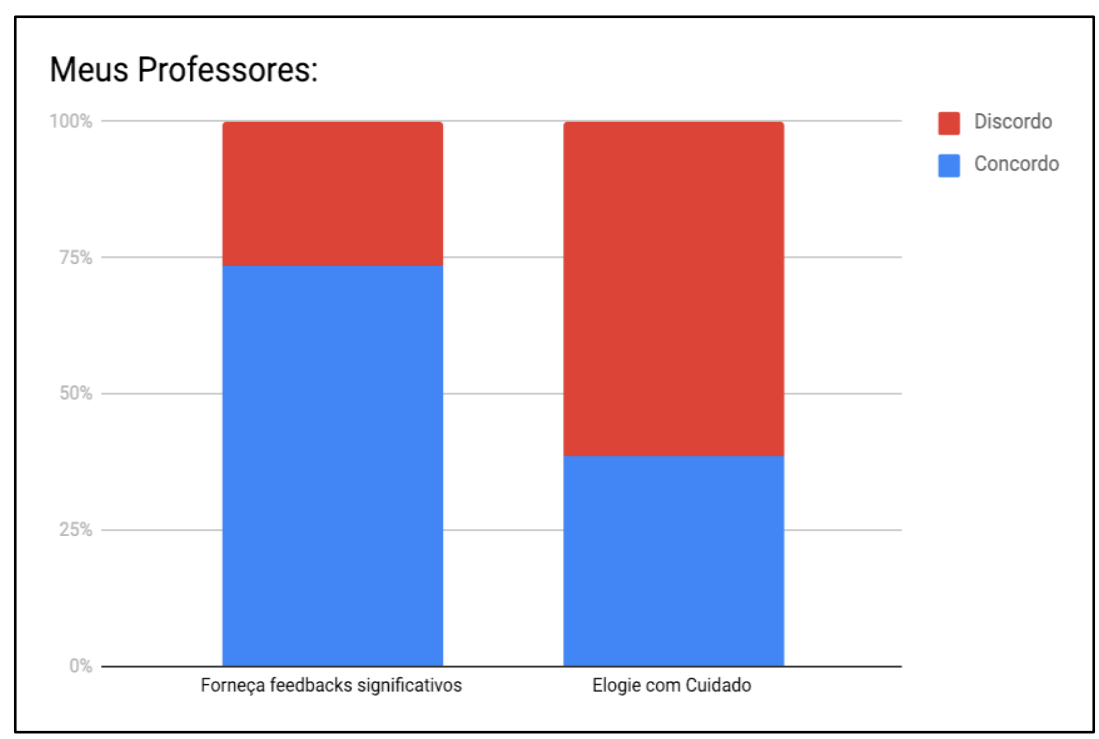

Fonte: Elaborado pelos autores.

Como último tópico da investigação, apresentamos cinco afirmativas aos sujeitos da pesquisa que deveriam escalar as atividades mencionadas em relação à sua frequência de prática, sendo o primeiro nível atitudes que sempre toma, seguido de atitudes que toma frequentemente, raramente, e por fim, atitudes que nunca são tomadas pelos estudantes. Conforme apresentado no gráfico 12, o feedback significativo, e, os elogios cuidadosos, são os itens que sempre são utilizados pela comunidade acadêmica da área.

Gráfico 12: avaliação de frequência do uso de práticas de desenvolvimento de mentalidade de crescimento: estudantes

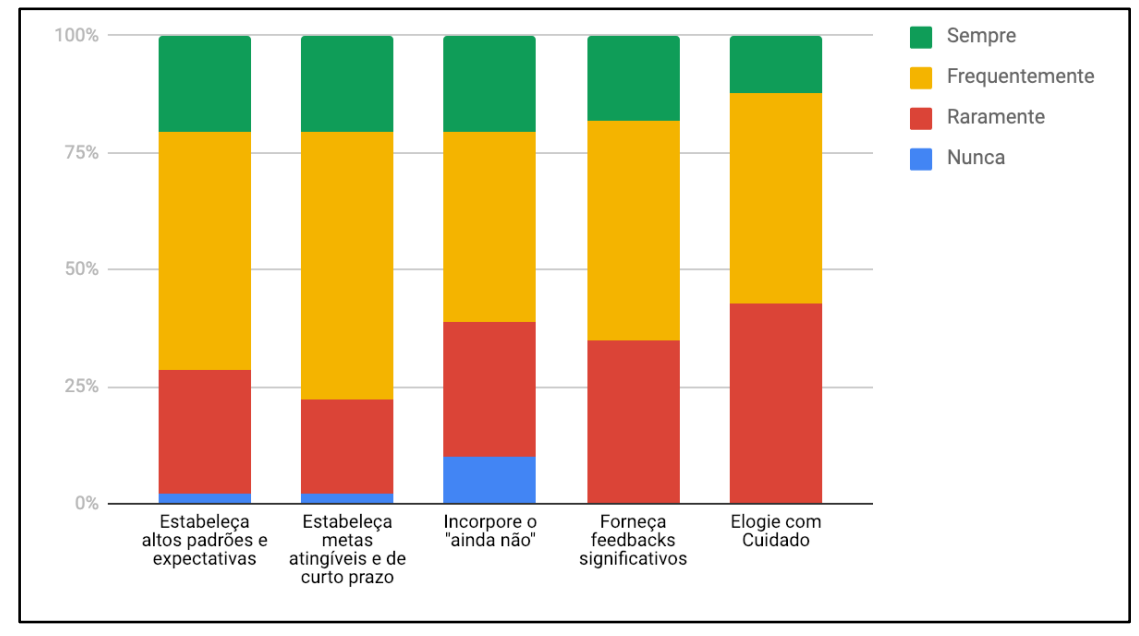

Fonte: Elaborado pelos autores. 


\section{Sensação de Pertencimento ao Curso/Área}

Conforme apontam estudos mencionados na parte introdutória deste trabalho, o senso de pertencimento é um fator de extrema importância e impacto na mentalidade acadêmica de estudantes. Por esse motivo, este ponto da investigação buscou demonstrar se estudantes e professores da área do design percebiam que colegas e alunos passaram por situações em que se sentiram não pertencentes à comunidade ou ao grupo. Num segundo momento, foram questionados sobre a procura de ajuda especializada para lidar com a situação.

No gráfico 13, vemos que os sentimentos ligados à incerteza do pertencimento ao grupo é um fator preocupante na área do design. Poucos estudantes e professores relatam nunca terem percebido o sentimento de não pertencimento, porém, quase $50 \%$ dos professores apontam que frequentemente seus alunos apresentam esses sentimentos e, entre os estudantes mais de $25 \%$ confirmam essa frequência.

Gráfico 13: avaliação sobre sentimentos de não pertencimento.

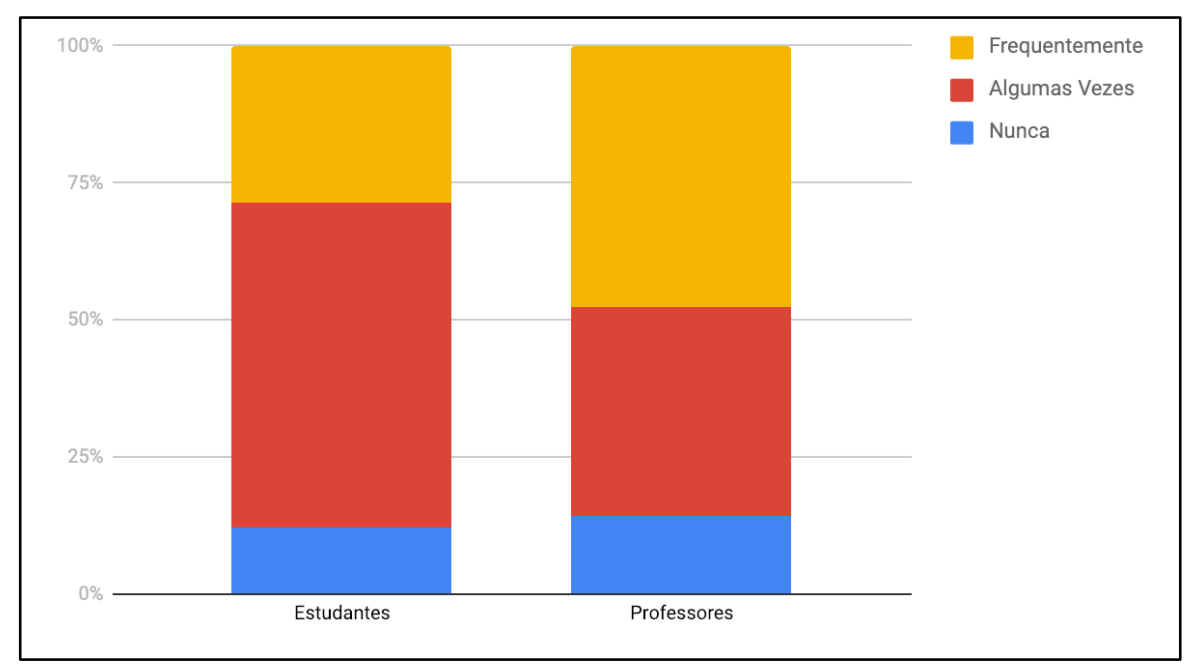

Fonte: Elaborado pelos autores.

Devido à importância desse tema, ressalta-se também que mais de 50\% dos estudantes reportam que algumas vezes já se sentiram não pertencentes ao grupo ou à comunidade. Esta realidade desvendada pela pesquisa, ainda é agravada quando percebemos que poucos estudantes têm acesso há algum tipo de ajuda especializada.

Como podemos ver no gráfico 14 , mais de $75 \%$ dos estudantes que se sentem não pertencentes ao curso ou ao grupo, não buscaram ajuda para lidar com a situação. Quando questionados, mais de 50\% dos professores da área do Design, relatam não terem procurado ajuda para os alunos com os sentimentos citados acima. 
Gráfico 14: avaliação sobre procura de ajuda em caso de sentimentos de não pertencimento.

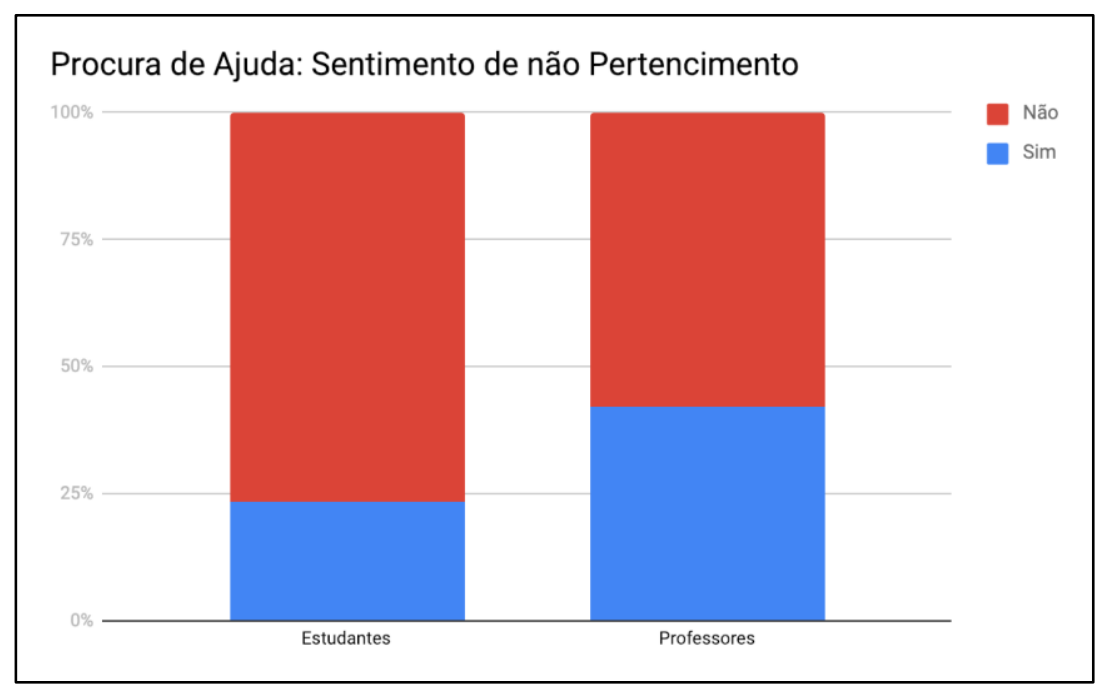

Fonte: Elaborado pelos autores.

\section{Conclusões}

Os principais achados dessa investigação, em relação à percepção de estudantes e professores de design, no que diz respeito as afirmativas que representam a mentalidade acadêmica de estudantes, são ligados a noção de que o aprendizado significativo requer esforço confusão e até mesmo erros. O fato da maioria dos professores assumir uma posição de discordância em relação a essa afirmação, mostra que possivelmente esses profissionais não estão atualizados em relação à ciência do aprendizado, ou ainda, pode ser inferido que a parte de formação de professores na área do design tem deixado a desejar.

Em relação aos fatores não cognitivos que mais impactam o ensino do Design percebemos que a perseverança acadêmica e as estratégias de aprendizagem devam ser ajustadas. Além do contexto sociocultural, relatado por professores, habilidades sociais também são pontos de destaque e merecem ser melhor abordadas nos cursos de design.

O ponto de maior destaque em relação ao desenvolvimento de uma mentalidade acadêmica de crescimento está relacionado ao estabelecimento de elevados padrões e expectativas tanto por professores como alunos. Em relação a outro tema, o senso de pertencimento, nota-se que a área do design apresenta elevados índices, o que pode se tornar motivo de preocupação somando-se ao fato de que pouca ajuda especializada é direcionada a essas ocorrências.

Os principais pontos dos resultados alcançados por essa pesquisa, mostram que existem ajustes e mudanças a serem feitas em modelos pedagógicos da área do design. De posse desses resultados, membros da comunidade acadêmica da área, podem dedicar-se diretamente aos pontos evidenciados a partir da mudança de práticas pedagógicas, instrucionais, ou até mesmo, no desenvolvimento de tecnologias educacionais para transpor os obstáculos encontrados. 


\section{Referências}

Yeager, D. S., Trzesniewski, K. H., \& Dweck, C. S. (2013). An Implicit Theories of Personality Intervention Reduces Adolescent Aggression in Response to Victimization and Exclusion. Child Development, 84(3), 970-988. https://doi.org/10.1111/cdev.12003

Hershkovitz, A., \& Forkosh-Baruch, A. (2013). Student-teacher relationship in the facebook era: The student perspective. International Journal of Continuing Engineering Education and Life-Long Learning, 23(1), 33-52. https://doi.org/10.1504/IJCEELL.2013.051765

Farrington, C. A., Roderick, M., Allensworth, E., Nagaoka, J., Keyes, T. S., Johnson, D. W., \& Beechum, N. O. (2012). Noncognitive Report--literature review, (June).

Dweck, C., Walton, G. M., \& Cohen, G. L. (2011). Academic tenacity: Mindset and skills that promote long-term learning. Gates Foundation. Seattle, WA: Bill \& Melinda Gates Foundation, 1-43. $\quad$ Retrieved from http://web.stanford.edu/ gwalton/home/Welcome_files/DweckWaltonCohen_201 4.pdf

Walton, G. M., Cohen, G. L., Cwir, D., \& Spencer, S. J. (2012). Mere belonging: The power of social connections. Journal of Personality and Social Psychology, 102(3), 513-532. https://doi.org/10.1037/aoo25731

Dunlosky, J., Rawson, K. A., Marsh, E. J., Nathan, M. J., \& Willingham, D. T. (2013). Improving students' learning with effective learning techniques: Promising directions from cognitive and educational psychology. Psychological Science in the Public Interest, Supplement, 14(1), 4-58. https://doi.org/10.1177/1529100612453266

Yeager, D. S., Johnson, R., Spitzer, B. J., Trzesniewski, K. H., Powers, J., \& Dweck, C. S. (2014). The far-reaching effects of believing people can change: Implicit theories of personality shape stress, health, and achievement during adolescence. Journal of Personality and Social Psychology, 106(6), 867-884. https://doi.org/10.1037/a0036335

\section{Biografia Resumida}

Ivan Mota Santos: Bacharel em Design de Produtos (Ed/UEMG), Mestre em Design (Ed/UEMG), Doutorando em Design (Ed/UEMG). Professor Assistente no Instituto de Artes e Design, Universidade Federal de Juiz de Fora (UFJF/Juiz de 
Fora/Brasil). Fundador do "Núcleo de Virtualidades e Ensaios em Design" (NUVEN/IAD/UFJF).

Lattes: http://lattes.cnpq.br/7460332013379987

Contato: ivan.santos@design.ufjf.br

Sebastiana Luiza Bragança Lana: Possui graduação em Geologia pela UFMG (1977), PhD em Engineering Materials - University of Sheffield (1994) e doutorado (1997) e pós-doutorado em Química pela UFMG. Membro do Corpo Docente permanente do PPGD da UEMG. Co-coordenadora do "Centro de Estudos e Tecnologia em Design”, CEDTec/ED/UEMG; Membro do colegiado fundador, professor permanente da REDEMAT: Consórcio entre as instituições UFOP/UEMG; integra o grupo de pesquisas do CPqd e o DIT- Núcleo de Pesquisa em Design Inovação e Tecnologia, ambos da UEMG.

Lattes: http://lattes.cnpq.br/o048231057293415

Contato: sebastiana.lana@gmail.com 